\title{
Excessive visceral fat accumulation in advanced chronic obstructive pulmonary disease
}

This article was published in the following Dove Press journal:

International Journal of COPD

5 August 20II

Number of times this article has been viewed

\author{
Ryuko Furutate' \\ Takeo Ishii I,2 \\ Ritsuko Wakabayashi' \\ Takashi Motegi ${ }^{1,2}$ \\ Kouichi Yamada ${ }^{1,2}$ \\ Akihiko Gemma ${ }^{2}$ \\ Kozui Kida ${ }^{1,2}$ \\ 'Respiratory Care Clinic, \\ Nippon Medical School, \\ Kudan-Minami, Chiyoda-ku, Tokyo, \\ Japan; ${ }^{2}$ Department of Internal \\ Medicine, Division of Pulmonary \\ Medicine, Infectious Diseases and \\ Oncology, Nippon Medical School, \\ Sendagi, Bunkyo-ku, Tokyo, Japan
}

Correspondence: Kozui Kida

Respiratory Care Clinic, Nippon Medical School, 4-7-I5 Kudan-Minami,

Chiyoda-ku, Tokyo 102-0074, Japan

Tel +8I-3-5276-2325

Fax +8I-3-5276-2326

Email kkida@nms.ac.jp
Background: Previous studies have suggested links between chronic obstructive pulmonary disease (COPD), cardiovascular disease, and abdominal obesity. Although abdominal visceral fat is thought to be associated with cardiovascular risk factors, the degree of visceral fat accumulation in patients with COPD has not been directly studied. The aim of this study was to investigate the abdominal visceral fat accumulation and the association between visceral fat and the severity and changes in emphysema in COPD patients.

Methods: We performed clinical and laboratory tests, including pulmonary function, dyspnea score, and the six-minute walking test in COPD patients $(\mathrm{n}=101)$ and control, which included subjects with a smoking history but without airflow obstruction $(n=62)$. We used computed tomography to evaluate the abdominal visceral fat area (VFA), subcutaneous fat area (SFA), and the extent of emphysema.

Results: The COPD group had a largerVFA than the control group. The prevalence of non-obese subjects with an increased VFA was greater in the Global Initiative for Chronic Obstructive Lung Disease Stages III and IV than in the other stages of COPD. The extent of emphysema was inversely correlated with waist circumference and SFA. However, VFA did not decrease with the severity of emphysema. VFA was positively correlated with the degree of dyspnea.

Conclusion: COPD patients have excessive visceral fat, which is retained in patients with more advanced stages of COPD or severe emphysema despite the absence of obesity.

Keywords: abdominal obesity, chronic obstructive pulmonary disease, emphysema, visceral fat

\section{Introduction}

Chronic obstructive pulmonary disease (COPD) is a disease with systemic comorbid conditions including hypertension, diabetes mellitus, and cardiovascular diseases due to systemic inflammation. ${ }^{1-3}$ Cardiovascular disease, which is often related to obesity, accounts for approximately $30 \%$ of mortality in more advanced COPD patients who tend to have muscle loss. ${ }^{4,5}$ Although the underlying mechanisms are presently unclear, chronic systemic inflammation is considered to increase susceptibility to cardiovascular disease in COPD patients. ${ }^{6}$

Several studies have showed that COPD patients have one or more components of metabolic syndrome, and that coexisting metabolic syndrome is associated with systemic inflammation and physical inactivity. ${ }^{7,8}$ Abdominal obesity, particularly visceral adiposity, is a key feature of metabolic syndrome and is associated with cardiovascular risk factors. ${ }^{9}$ This is because the accumulation of visceral fat causes endocrine disturbances such as adipokine dysregulation. ${ }^{10}$ Features of acute-phase activation and low-grade inflammation, including elevated levels of fibrinogen, 
C-reactive protein, and interleukin (IL)-6, are particularly associated with central or visceral obesity. ${ }^{11}$ Adiponectin is an anti-inflammatory cytokine that is believed to control cardiovascular diseases. High levels of IL-6 or tumor necrosis factor- $\alpha$ and low levels of adiponectin are observed when there is an excess accumulation of visceral fat. ${ }^{11}$

In general, physical inactivity is one of the most important determinants of the accumulation of visceral fat, ${ }^{12}$ which is commonly observed in COPD patients. ${ }^{13}$ Although this information suggests an association between visceral adiposity and COPD, visceral fat accumulation in COPD patients has not been directly investigated.

Abdominal obesity is generally assessed by anthropometric measurements such as waist circumference and waist-to-hip ratio to estimate the amount of abdominal adipose tissue; however, it has been reported that the association between cardiovascular risk factors and visceral fat measured directly with computed tomography (CT) is stronger than the associations between these factors and such anthropometric measurements. ${ }^{9}, 14$

We hypothesized that COPD patients have excessive visceral fat and that its accumulation has systemic consequences such as cardiovascular disease. Furthermore, visceral fat accumulation is probably retained in patients with more advanced stages of COPD and with severe emphysema, and this might continuously induce systemic comorbidities. To examine our hypotheses, we compared visceral fat accumulation in COPD and control groups by using CT. With regard to the COPD group, we also investigated the relationship between visceral fat accumulation and the extent of emphysema, as well as the severity of COPD.

\section{Methods}

\section{Subjects}

For the present cross-sectional study, we enrolled 163 consecutive Japanese men who visited the Respiratory Care Clinic, Nippon Medical School, Tokyo, Japan, from January to December 2007. The inclusion criteria were as follows: (1) exertional dyspnea, prolonged cough, or expectoration compatible with clinical symptoms of COPD, as described in the Global Initiative for Chronic Obstructive Lung Disease (GOLD) guidelines ${ }^{15}$ and (2) current or previous smoker (number of pack-years $\geq 20$ ). We excluded those who had (1) a history of atopy or any apparent clinical features of asthma, (2) received any systemic corticosteroid regimen in the preceding 3 months, (3) experienced exacerbation during the preceding 3 months, or (4) had other respiratory diseases such as bronchiectasis or pulmonary fibrosis.
We divided the subjects into a COPD group and a control group according to the results of pulmonary function tests; the COPD group included those who had a ratio of forced expiratory volume in 1 second $\left(\mathrm{FEV}_{1}\right)$ to forced vital capacity (FVC) of $<0.7$ after bronchodilator administration. ${ }^{15}$

The present study was approved by the Ethics Committee of Nippon Medical School, and all patients were enrolled after they had provided appropriate informed consent.

\section{Pulmonary function testing}

Pulmonary functional parameters, including postbronchodilator $\mathrm{FEV}_{1}$, carbon monoxide diffusing capacity, vital capacity, and FVC, were measured according to the American Thoracic Society (ATS) guidelines ${ }^{16}$ by using computer-coupled equipment for lung function testing (Chestac; Chest Co., Tokyo, Japan). Reference post-bronchodilator values were based on standards of the Japanese Respiratory Society. ${ }^{17}$ COPD severity was classified as Stage I, II, III, or IV, depending on the $\mathrm{FEV}_{1} \%$ predicted, as described in the GOLD guidelines. ${ }^{15}$

\section{Arterial blood gases}

Arterial blood was drawn from a radial artery while the subjects were breathing room air in a seated position. Arterial partial pressures of oxygen and carbon dioxide $\left(\mathrm{PaO}_{2}\right.$ and $\mathrm{PaCO}_{2}$, respectively) were analyzed with a blood gas analyzer (Stat Profile ${ }^{\circledR}$ pHOx ${ }^{\circledR}$ Plus; Nova Biomedical, MA).

\section{Modified Medical Respiratory Council dyspnea scale}

The degree of dyspnea was assessed using the Modified Medical Respiratory Council (MMRC) dyspnea scale. ${ }^{18}$

\section{Exercise capacity}

The 6-minute walk test (6MWT) was performed according to ATS standards, ${ }^{19}$ during which oximetry was performed at 10-second intervals with a pulse oximeter (PULSOX; Teijin Pharma Ltd, Tokyo, Japan).

\section{Anthropometry}

Body height and weight were measured (BWB-800 and Rainbow scale, respectively; Tanita Co, Tokyo, Japan). Body mass index (BMI) was calculated as the ratio of body weight to height $\left(\mathrm{m}^{2}\right)$. The criteria for BMI classification of the Japan Society for the Study of Obesity were applied as follows: BMI $<18.5 \mathrm{~kg} / \mathrm{m}^{2}$, underweight; $18.5 \mathrm{~kg} / \mathrm{m}^{2} \leq \mathrm{BMI}<25 \mathrm{~kg} / \mathrm{m}^{2}$, normal weight; 
$25 \mathrm{~kg} / \mathrm{m}^{2} \leq \mathrm{BMI}<30 \mathrm{~kg} / \mathrm{m}^{2}$, obese; and BMI $\geq 30 \mathrm{~kg} / \mathrm{m}^{2}$, severely obese. ${ }^{20}$ Waist circumference at the umbilicus level was measured during the late exhalation phase while standing. Fat-free mass (FFM) and fat mass (FM) were measured by bioelectrical impedance analysis at frequencies of 5, 50, 250, and $500 \mathrm{kHz}$ (InBody 3.2; Biospace Co Ltd, Seoul, Republic of Korea). The FFM index (FFMI) and FM index (FMI) were calculated as the ratio of FFM or FM to height $\left(\mathrm{m}^{2}\right)$, respectively.

\section{Comorbidities}

The degree of comorbidity was determined using the Charlson index, ${ }^{21}$ which has been shown to be associated with mortality in COPD patients. ${ }^{22}$ Higher scores in the Charlson index indicate more coexisting conditions.

\section{Analysis of emphysema by computed tomography}

The percentage of low-attenuation area (LAA\%) in highresolution CT (HRCT) images was calculated as described previously. ${ }^{23}$ HRCT was performed using a LightSpeed Pro16 CT scanner (General Electric Co, Tokyo, Japan) with the following settings: $1.25-\mathrm{mm}$ collimation, 0.8 -second scan time (rotation time), $120 \mathrm{kV}$, and 100-600 mA. The cut-off level between normal lung density and the LAA was defined as $-940 \mathrm{HU}$.

\section{Analysis of the visceral fat area and subcutaneous fat area by computed tomography}

The visceral fat area (VFA) and subcutaneous fat area (SFA) were assessed using cross-sectional $\mathrm{CT}$ scans at the umbilicus level as described previously. ${ }^{24}$ The VFA cut-off value for visceral adiposity in Japanese men according to the Japan Society for the Study of Obesity is $100 \mathrm{~cm}^{2} .^{20}$

\section{Parameters related to metabolic syndrome}

Waist circumference was measured as described above. Systolic and diastolic blood pressures were measured in the right arm, employing the conventional cuff method using an automated sphygmomanometer (BP-203RV IIIB; Omron-Colin Co Ltd, Tokyo, Japan). Blood samples were collected from an antecubital vein after overnight fasting; serum triglyceride, high-density lipoprotein (HDL)-cholesterol, and fasting blood glucose levels were measured.

\section{Statistical analysis}

Differences in quantitative variables between the control and COPD groups were assessed for significance by using the unpaired Student's $t$-test or the Mann-Whitney $U$-test, where appropriate. Qualitative data were analyzed using the chi-square test. The Kruskal-Wallis test and one-way analysis of variance (ANOVA), with the Tukey-Kramer procedure for post-hoc multivariate comparisons of means, were used to compare non-parametric and parametric data, respectively, among GOLD stages. The Pearson correlation coefficient or the Spearman rank correlation coefficient was used to evaluate relationships between LAA $\%$ and VFA, SFA, BMI, waist circumference, FMI, and FFMI, where appropriate. All statistical tests were 2 -tailed, and $P$ values $<0.05$ were considered significant. Data were analyzed using SPSS (v 11.0.1 for Windows; SPSS Inc, Chicago, IL).

\section{Results}

\section{Subject characteristics}

The COPD group $(\mathrm{n}=101)$ had a higher smoking index than the control group $(n=62)$ (Table 1). No significant differences in BMI or waist circumference were observed between the two groups.

Table I Subject characteristics

\begin{tabular}{|c|c|c|c|}
\hline & Control & COPD & $P$ value \\
\hline Subjects (n) & 62 & 101 & - \\
\hline Age (years) & $68.5(60.0-75.0)$ & $69.0(64.0-75.0)$ & 0.126 \\
\hline $\begin{array}{l}\text { Smoking index } \\
\text { (pack-years) }\end{array}$ & $50.0(30.0-69.4)$ & $70.0(40.5-102.5)$ & 0.004 \\
\hline $\mathrm{FEV}_{1}(\mathrm{~L})$ & $2.7 \pm 0.7$ & $1.7 \pm 0.6$ & $<0.0001$ \\
\hline $\mathrm{FEV}_{1} / \mathrm{FVC}(\%)$ & $77.5(74.1-83.0)$ & $50.7(42.3-59.2)$ & $<0.0001$ \\
\hline FEV $\%$ predicted (\%) & $89.9 \pm 15.7$ & $58.6 \pm 19.3$ & $<0.0001$ \\
\hline DLCO/VA & $3.6 \pm 1.1$ & $2.7 \pm 0.9$ & $<0.0001$ \\
\hline $\mathrm{PaO}_{2}(\mathrm{mmHg})$ & $88.5 \pm 7.5$ & $80.6 \pm 10.5$ & $<0.0001$ \\
\hline $\mathrm{PaCO}_{2}(\mathrm{mmHg})$ & $41.5 \pm 4.2$ & $40.2 \pm 3.9$ & 0.067 \\
\hline LAA\% (\%) & $18.8 \pm 11.6$ & $33.6 \pm 13.2$ & $<0.0001$ \\
\hline BMI $\left(\mathrm{kg} / \mathrm{m}^{2}\right)$ & $23.0 \pm 3.4$ & $23.4 \pm 3.2$ & 0.451 \\
\hline $\begin{array}{l}\text { Waist } \\
\text { circumference }(\mathrm{cm})\end{array}$ & $84.8 \pm 9.6$ & $87.6 \pm 8.9$ & 0.070 \\
\hline FMI $\left(\mathrm{kg} / \mathrm{m}^{2}\right)$ & $5.3 \pm 1.9$ & $5.9 \pm 2.0$ & 0.037 \\
\hline FFMI $\left(\mathrm{kg} / \mathrm{m}^{2}\right)$ & $17.7 \pm 1.9$ & $17.5 \pm 1.7$ & 0.382 \\
\hline MMRC & $0.65 \pm 0.8$ & $1.16 \pm 1.0$ & 0.001 \\
\hline 6MWD (m) & $525.8 \pm 79.8$ & $460.3 \pm 105.0$ & $<0.0001$ \\
\hline Charlson index & $2.5 \pm 1.0$ & $2.8 \pm 0.9$ & 0.100 \\
\hline
\end{tabular}

Note: Data are presented as the mean \pm standard deviation, median (interquartile range), or numbers.

Abbreviations: 6MWD, six-minute walk test distance; BMI, body mass index; COPD, chronic obstructive pulmonary disease; DLCO, carbon monoxide diffusion capacity; $\mathrm{FEV}_{1}$, forced expiratory volume in I second; FFMI, fat-free mass index; FMI, fat mass index; FVC, forced vital capacity; GOLD, Global Initiative for Chronic Obstructive Lung Disease; LAA\%, percentage of low-attenuation area; MMRC, modified Medical Research Council; $\mathrm{PaO}_{2}$, partial pressure of oxygen; $\mathrm{PaCO}_{2}$, partial pressure of carbon dioxide; VA, alveolar volume. 
Regarding metabolic parameters, the COPD group had significantly higher systolic blood pressure and lower fasting glucose levels than the control group. No significant differences were observed between the two groups with respect to diastolic blood pressure, triglycerides, or HDL-cholesterol levels. Significantly more subjects in the COPD group were receiving treatment for hypertension or dyslipidemia (Table 2).

\section{Visceral fat area}

The VFA was significantly greater in the COPD group than in the control group $(P=0.023)$ (Figure 1). The prevalence of patients with VFA $\geq 100 \mathrm{~cm}^{2}$ (the cut-off value for abdominal obesity) in the COPD and control groups was $52.5 \%$ and $38.7 \%$, respectively. No difference in SFA was observed between the two groups (data not shown).

\section{Muscle depletion and visceral fat accumulation}

Data on body composition and abdominal fat areas at various COPD stages are shown in Table 3. Stages III and IV were combined into one group designated "Stages III+IV", because the number of subjects in Stage IV was so small that these subjects could not be examined separately.

The FFMI in Stages III+IV was significantly lower than that in both Stage II $(P=0.046)$ and Stage I $(P=0.060)$. This suggests that FFMI decreases with the progression of COPD. In contrast, VFA tended to increase with COPD progression, although not all differences were statistically significant. The percentages of non-obese patients with VFA $\geq 100 \mathrm{~cm}^{2}$ in Stages I, II, and III+IV were $15.8 \%, 19.0 \%$, and $45.0 \%$, respectively. The prevalence of nonobese patients with VFA $\geq 100 \mathrm{~cm}^{2}$ in Stages III+IV was significantly higher than that in the other stages $(P=0.013)$.

\section{Relationships between emphysema and waist circumference, subcutaneous fat area, and visceral fat area}

Although the LAA\% was inversely correlated with waist circumference $(P=0.002, r=-0.322)$ and SFA $(P<0.0001$, $r=-0.454$ ) (Figure 2A and B, respectively), it was not correlated with VFA $(P=0.194$, Rho $=-0.125)$ (Figure 2C). The LAA \% was also inversely correlated with BMI $(P<0.0001$, $r=-0.507)$, FMI $(P<0.0001, r=-0.385)$, and FFMI $(P<0.0001, r=-0.491)$.

\section{Visceral fat area and dyspnea and exercise capacity}

VFA was positively correlated with the MMRC scale score $(P=0.013$, Rho $=0.252)$ but not with the 6MWD, or minimum oxygen or the change in oxygen saturation during the $6 \mathrm{MWT}$.

\section{Discussion}

The primary finding of the present study is that COPD patients have excessive visceral fat and its accumulation is retained in the more advanced stages of COPD and severe emphysema despite the absence of obesity. To the best of our knowledge, there has been no previous study of the association between COPD and abdominal visceral fat accumulation measured directly by $\mathrm{CT}$.

The present study yields several interesting and novel findings. First, the COPD group had a larger VFA than the control group, although there was no difference in BMI or waist circumference between the two groups. Furthermore, the median VFA in the COPD group was $\geq 100 \mathrm{~cm}^{2}$. This is the cut-off value for VFA in Japanese men. ${ }^{20}$ This finding may be related to the significantly higher prevalence of subjects receiving treatment for hypertension or dyslipidemia in the COPD group than in the control group. A previous

Table 2 Comparison of metabolic profiles between the COPD and control groups

\begin{tabular}{llll}
\hline & Control & COPD & P value \\
\hline Subjects $(\mathrm{n})$ & 62 & 101 & - \\
Systolic blood pressure $(\mathrm{mmHg})$ & $129.3 \pm 14.9$ & $135.9 \pm 18.3$ & 0.033 \\
Diastolic blood pressure $(\mathrm{mmHg})$ & $79.7 \pm 10.4$ & $81.9 \pm 11.7$ & 0.275 \\
Fasting glucose $(\mathrm{mg} / \mathrm{dL})$ & $102.5(88.5-116.5)$ & $95.0(87.0-103.0)$ & 0.005 \\
Triglycerides $(\mathrm{mg} / \mathrm{dL})$ & $104.0(62.0-146.0)$ & $112.0(75.5-148.5)$ & 0.498 \\
HDL-cholesterol $(\mathrm{mg} / \mathrm{dL})$ & $56.0(45.0-67.0)$ & $56.5(44.5-68.5)$ & 0.832 \\
Hypertension treatment & $17(27.4)$ & $50(49.5)$ & 0.005 \\
Diabetes treatment & $1 \mathrm{I}(17.7)$ & $15(14.9)$ & 0.625 \\
Dyslipidemia treatment & $10(16.1)$ & $44(43.6)$ & $<0.0001$ \\
\hline
\end{tabular}

Note: Data are presented as the mean \pm standard deviation, median (interquartile range), or numbers (\%).

Abbreviations: COPD, chronic obstructive pulmonary disease; HDL, high-density lipoprotein. 


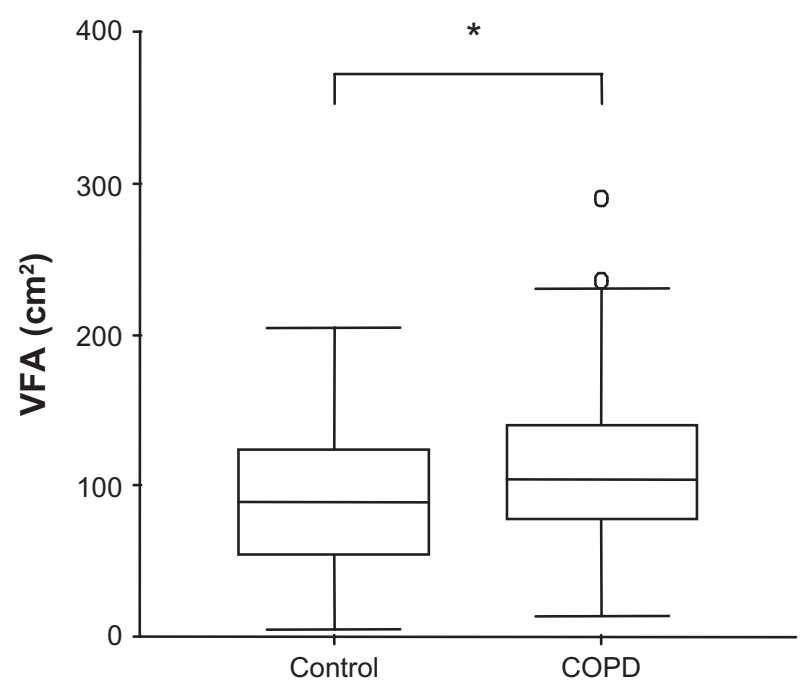

Figure I The difference in the visceral fat area (VFA) between the chronic obstructive pulmonary disease $(C O P D)$ group $(n=101)$ and the control group $(n=62)$. Notes: Data are presented as medians (COPD, 104.3; control, 89.8). Boxes represent interquartile ranges (COPD, 78.2-139.8; control, 55.6-123.2), and whiskers represent standard deviations. $\mathrm{O}$ : extreme outliers. $* P=0.023$.

investigation by the Japan Society for the Study of Obesity also suggests that the risk of having at least one obesityrelated disorder such as dyslipidemia, hypertension, or hyperglycemia increases at VFA $\geq 100 \mathrm{~cm}^{2}$; furthermore, the number of obesity-related disorders increases with an increase in VFA. ${ }^{20}$

Second, the prevalence of non-obese patients with excessive visceral fat was highest in Stages III+IV of COPD. In addition, patients with COPD and severe emphysema retained visceral fat despite the absence of obesity. Such patients are often found to be malnourished. ${ }^{25}$ Indeed, decreased skeletal muscle mass was observed in the more severe COPD stages. Furthermore, BMI, waist circumference, FFMI, FMI, and SFA decreased with increasing emphysematous severity in the present study. Similarly, Ogawa et al have reported that BMI and subcutaneous fat are lower in predominantly emphysematous COPD patients, although thoracic subcutaneous fat was measured rather than abdominal fat. ${ }^{26}$ Previously, we reported that the extent of emphysema observed in HRCT is associated with FFM and FM loss in COPD in a different cohort from that in the present study. ${ }^{27}$

Taken together, these results indicate that COPD patients show simultaneous muscle loss and excess visceral fat accumulation, particularly in the more severe stages of COPD and emphysema. There are several possible explanations for this observation. It has been reported that skeletal muscle mass in advanced stages of COPD decreases with increased energy expenditure, physical inactivity owing to dyspnea, decreased exercise capacity, inadequate diet, and/or systemic inflammation. ${ }^{13,28,29}$ Decreased skeletal muscle mass may result in further physical inactivity, leading to excess visceral fat accumulation, especially in the more advanced stages of COPD and/or severe emphysema.

Last, visceral fat accumulation in COPD increased with the severity of dyspnea in the present study. This may be related to physical inactivity. Serres et al showed that physical inactivity is a consequence of the so-called dyspnea spiral, ${ }^{30}$ in which COPD patients tend to adopt a sedentary lifestyle to avoid dyspnea. However, our analysis did not show a significant correlation between 6MWD and visceral fat accumulation. Although the 6MWD could be indicative of exercise capacity, it does not necessarily reflect the total amount of physical activity in daily life. Further studies are needed to assess this possible association by using physical activity monitors or accelerometers.

Our findings may partially explain the increased risk of cardiovascular diseases in COPD patients, especially in those with more advanced stages. COPD patients, even those with a normal BMI, may have an increased risk of cardiovascular disease owing to excessive accumulation of visceral fat. In this regard, careful assessment of abdominal obesity is

Table 3 Differences in variables related to muscle and fat between the GOLD stages of COPD

\begin{tabular}{|c|c|c|c|c|}
\hline & Stage I & Stage II & Stages III+IV & $P$ value \\
\hline Subjects (n) & 19 & 42 & 40 & - \\
\hline $\mathrm{FMI}\left(\mathrm{kg} / \mathrm{m}^{2}\right)$ & $5.6(4.3-6.9)$ & $6.2(5.1-7.0)$ & $5.8(4.8-6.6)$ & 0.713 \\
\hline FFMI $\left(\mathrm{kg} / \mathrm{m}^{2}\right)$ & $18.0 \pm 1.3$ & $17.8 \pm 1.9$ & $16.9 \pm 1.6$ & 0.022 \\
\hline $\mathrm{BMI}\left(\mathrm{kg} / \mathrm{m}^{2}\right)$ & $23.7(22.3-25.4)$ & $24.7(21.9-26.5)$ & $22.4(21.1-23.8)$ & 0.463 \\
\hline Waist circumference $(\mathrm{cm})$ & $87.4 \pm 8.8$ & $87.7 \pm 8.4$ & $87.7 \pm 9.8$ & 0.990 \\
\hline VFA $\left(\mathrm{cm}^{2}\right)$ & $97.2 \pm 43.5$ & $107.2 \pm 48.2$ & $125.3 \pm 60.5$ & 0.117 \\
\hline SFA $\left(\mathrm{cm}^{2}\right)$ & $107.7 \pm 47.2$ & $121.4 \pm 49.6$ & $110.0 \pm 47.2$ & 0.454 \\
\hline
\end{tabular}

Note: Data are presented as the mean \pm standard deviation, median (interquartile range), or numbers.

Abbreviations: BMI, body mass index; COPD, chronic obstructive pulmonary disease; FFMI, fat-free mass index; FMI, fat mass index; GOLD, Global Initiative for Chronic Obstructive Lung Disease; SFA, subcutaneous fat area; VFA, visceral fat area. 
A

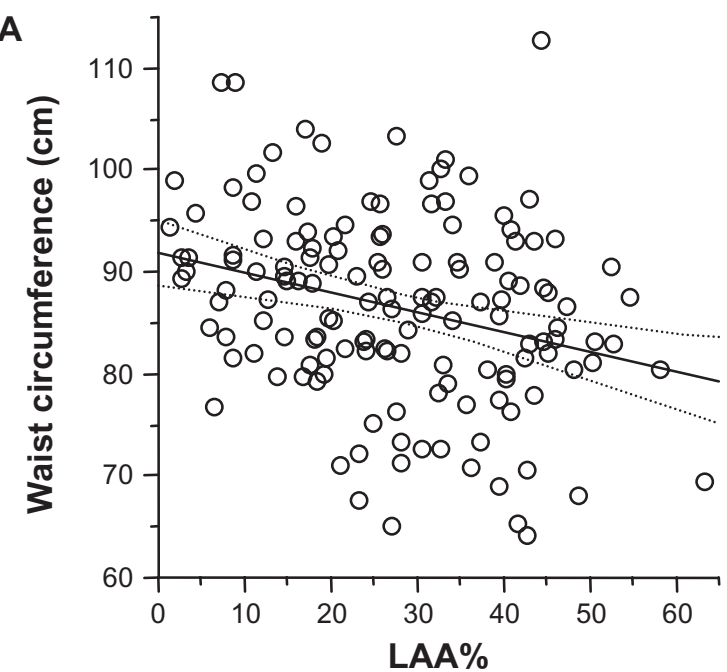

B

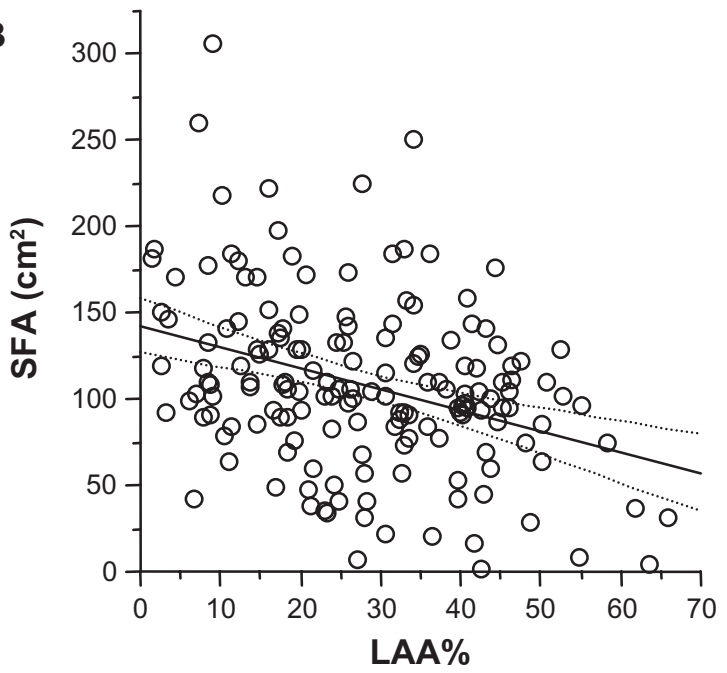

C

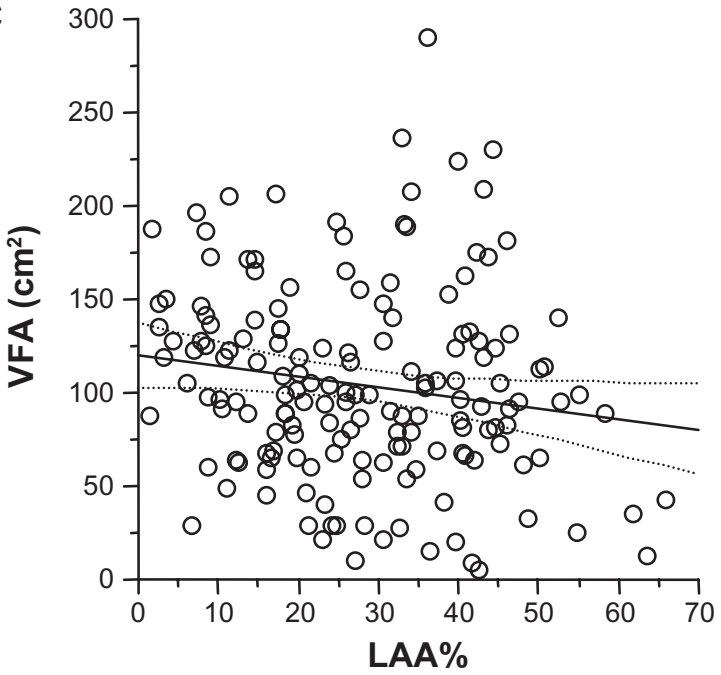

Figure 2 Relationships between the percentage of low-attenuation area (LAA\%) and waist circumference, visceral fat area (VFA), and subcutaneous fat area (SFA) in patients with chronic obstructive pulmonary disease (COPD). Significant correlations were observed between the LAA\% and (A) waist circumference $(r=-0.322, P=0.002)$ and (B) SFA $(r=-0.455, P<0.0001)$ but not (C) VFA (Rho $=-0.125, P=0.194)$. The two dashed curves surrounding the linear regression line (solid line) in each panel represent the $95 \%$ confidence intervals. needed for non-obese COPD patients, especially those at more advanced stages or with severe emphysema, because they tend to show abdominal subcutaneous fat loss.

Although it is often hypothesized that systemic inflammation in COPD is the result of a "spill-over" of airway inflammation into the systemic circulation, ${ }^{31}$ adipose tissuemediated inflammation in COPD has also recently been proposed. ${ }^{32}$ Visceral adiposity is generally associated with adipocyte dysfunction, leading to systemic inflammation. ${ }^{33}$ In a previous study, adipocyte dysfunction was found to be associated with adipose tissue hypoxia. ${ }^{34}$ Therefore, we hypothesize that excessive visceral fat is another source of systemic inflammation in COPD and contributes toward altered body composition. In particular, patients with reduced pulmonary function, who also tend to be hypoxic, may be more susceptible to this effect, because systemic hypoxia is also associated with systemic inflammation. ${ }^{35}$

The present study has raised several questions, which need to be explored in future studies. We should investigate the prognosis or clinical outcomes in COPD patients who have normal BMI/waist circumference, increased visceral fat, and depleted muscle. We need also to investigate the influence of corticosteroids on visceral fat accumulation and the effects of pulmonary rehabilitation on COPD patients. Abdominal adipose tissue is considered to be a source of inflammation as described above, ${ }^{33}$ and is associated with insulin resistance and cardiovascular diseases. ${ }^{9}$ Moreover, FFMI is an even more important determinant of prognosis in patients with moderate to severe COPD than BMI. ${ }^{36}$ In this regard, we believed that a cohort of COPD patients with normal BMI/waist circumference, increased visceral fat, and depleted muscle as shown in the present study have a bad prognosis characterized by decreased activity of daily living and increased exacerbations or mortality. However, the role of adipose tissue in the pathogenesis of systemic inflammation in COPD has not yet been fully examined. In addition, COPD patients are often treated with glucocorticoids for exacerbations or with an inhalation in more advanced stages or in daily treatment for asthma. ${ }^{15}$ Although no patients in the present study received oral corticosteroids in the preceding 3 months of the evaluation, it should be noted that systemic corticosteroid therapy may induce visceral obesity as a result of glucocorticoid-mediated redistribution of stored energy and the stimulatory effect on intake. ${ }^{37}$ When it comes to a possible strategy for disease management, pulmonary rehabilitation is suggested in anticipation of not only increased muscle strength but also 
visceral fat loss. Visceral fat loss after aerobic exercise training improves glucose metabolism and is associated with the reversal of insulin resistance..$^{38}$ On the basis of the findings outlined above, we believe that further studies are needed to reveal the potential influence of visceral adiposity on the prognosis of COPD patients with normal $\mathrm{BMI} /$ waist circumference and the possible implications for corticosteroids and pulmonary rehabilitation in COPD.

Our study is subject to certain limitations. First, the VFA cut-off value of $100 \mathrm{~cm}^{2}$ was used on the basis of the accepted Japanese standard, ${ }^{20}$ because this is the only available value for healthy Japanese subjects. Second, in the present study, only Japanese men were enrolled to exclude the influence of gender differences in VFA. It is also likely that there are ethnic differences with respect to VFA; therefore, inter-ethnic differences need to be studied, and a larger sample should be used. A recent study has indicated the presence of an obesity epidemic in most but not all racial and ethnic groups. ${ }^{39}$ This suggests that additional studies involving other ethnic groups should be conducted. Last, the effects of excessive visceral fat on comorbidities, were not fully evaluated in this study. Further prospective studies are needed to investigate causal relationships between visceral fat accumulation and comorbidities.

In conclusion, COPD patients have excessive visceral fat, which is retained in patients with more advanced stages of COPD or severe emphysema despite the absence of obesity. The status of malnutrition appears to vary among COPD stages and phenotypes; therefore, different intervention regimens should be developed for COPD subtypes.

\section{Acknowledgments}

This study was supported by the Environmental Restoration and Conservation Agency of Japan (2007-2009). Editage, a division of Cactus Communications Pvt Ltd, Tokyo, Japan, edited this manuscript to ensure an acceptable standard of English.

\section{Disclosure}

None of the authors have financial or other conflicts of interest related to the contents of this paper.

\section{References}

1. Agustí AG, Noguera A, Sauleda J, Sala E, Pons J, Busquets X. Systemic effects of chronic obstructive pulmonary disease. Eur Respir J. 2003; 21(2):347-360.

2. Mannino DM, Braman S. The epidemiology and economics of chronic obstructive pulmonary disease. Proc Am Thorac Soc. 2007;4(7): $502-506$.
3. Johnston AK, Mannino DM, Hagan GW, Davis KJ, Kiri VA Relationship between lung function impairment and incidence or recurrence of cardiovascular events in a middle-aged cohort. Thorax. 2008;63(7):599-605.

4. McGarvey LP, John M, Anderson JA, Zvarich M, Wise RA. Ascertainment of cause-specific mortality in COPD: operations of the TORCH Clinical Endpoint Committee. Thorax. 2007;62(5):411-415.

5. Pardo Silva MC, De Laet C, Nusselder WJ, Mamun AA, Peeters A. Adult obesity and number of years lived with and without cardiovascular disease. Obesity (Silver Spring). 2006;14(7):1264-1273.

6. Sin DD, Man SF. Why are patients with chronic obstructive pulmonary disease at increased risk of cardiovascular diseases? The potential role of systemic inflammation in chronic obstructive pulmonary disease. Circulation. 2003;107(11):1514-1519.

7. Poulain M, Doucet M, Drapeau V, et al. Metabolic and inflammatory profile in obese patients with chronic obstructive pulmonary disease. Chron Respir Dis. 2008;5(1):35-41.

8. Watz H, Waschki B, Kristen A, et al. The metabolic syndrome in patients with chronic bronchitis and COPD: frequency and associated consequences for systemic inflammation and physical inactivity. Chest. 2009;136(4):1039-1046.

9. Fox CS, Massaro JM, Hoffmann U, et al. Abdominal visceral and subcutaneous adipose tissue compartments: association with metabolic risk factors in the Framingham Heart Study. Circulation. 2007;116(1): 39-48.

10. Matuzawa Y. Adiponectin: identification, physiology and clinical relevance in metabolic and vascular disease. Atheroscler Suppl. 2005; $6(2): 7-14$.

11. Yudkin JS. Adipose tissue, insulin action vascular disease: inflammatory signals. Int J Obes Relat Metab Disord. 2003;27(Suppl 3):S25-S28.

12. Molennar EA, Massaro JM, Jacques PF, et al. Association of lifestyle factors with abdominal subcutaneous and visceral adiposity: the Framingham Heart Study. Diabetes Care. 2009;32(3):505-510.

13. Pitta F, Troosters T, Spruit MA, Probst VS, Decramer M, Gosselink R. Characteristics of physical activities in daily life in chronic obstructive pulmonary disease. Am J Respir Crit Care Med. 2005;171(9): 972-977.

14. Nicklas BJ, Penninx BW, Ryan AS, Berman DM, Lynch NA, Dennis KE. Visceral adipose tissue cutoffs associated with metabolic risk factors for coronary heart disease in women. Diabetes Care. 2003; 26(5):1413-1420.

15. Global Initiative for Chronic Obstructive Lung Disease. Executive summary. Global strategy for the diagnosis, management and prevention of chronic obstructive pulmonary disease. http://www.goldcopd.com. Date last updated: March 2009. Accessed September 7, 2010.

16. American Thoracic Society. Standardization of spirometry, 1994 update Am J Respir Crit Care Med. 1995;152(3):1107-1136.

17. Japanese Respiratory Society. The predicted values of spirometry and arterial blood gas analysis in Japanese. J Jpn Resp Soc. 2001; 39:Appendix. Japanese.

18. Mahler DA, Wells CK. Evaluation of clinical methods for rating dyspnea. Chest. 1988;93(3):580-586.

19. ATS Committee on Proficiency Standards for Clinical Pulmonary Function Laboratories. ATS statement: guidelines for the six-minute walk test. Am J Respir Crit Care Med. 2002;166(1):111-117.

20. Examination Committee of Criteria for 'Obesity Disease' in Japan, Japan Society for the Study of Obesity. New criteria for 'obesity disease' in Japan. Circ J. 2002;66(1):987-992.

21. Charlson ME, Pompei P, Ales KA, MacKenzie CR. A new method of classifying prognostic comorbidity in longitudinal studies: development and validation. J Chronic Dis. 1987;40(5):373-383.

22. Almagro P, Calbo E, Ochoa de Echagüen A, et al. Mortality after hospitalization for COPD. Chest. 2002;121(5):1441-1448.

23. Motohashi N, Kimura K, Ishii T, et al. Emphysema on imaging is associated with quality of life in elderly patients with chronic obstructive pulmonary disease. Geriatr Gerontol Int. 2010;10(1):17-24. 
24. Yoshizumi T, Nakamura T, Yamane M, et al. Abdominal fat: standardized technique for measurement at CT. Radiology. 1999;211(1):283-286.

25. Steuten LM, Creutzberg EC, Vrijhoef HJ, Wouters EF. COPD as a multicomponent disease: inventory of dyspnoea, underweight, obesity and fat free mass depletion in primary care. Prim Care Respir J. 2006; 15(2):84-91.

26. Ogawa E, Nakano Y, Ohara T, et al. Body mass index in male patients with COPD: correlation with low attenuation areas on CT. Thorax. 2009;64(1):20-25.

27. Kurosaki H, Ishii T, Motohashi N, et al. Extent of emphysema on HRCT affects loss of fat-free mass and fat mass in COPD. Intern Med. 2009; 48(1):41-48.

28. Decramer M, De Benedetto F, Del Ponte A, Marinari S. Systemic effects of COPD. Respir Med. 2005;99(Suppl B):S3-S10.

29. Eid AA, Ionescu AA, Nixon LS, et al. Inflammatory response and body composition in chronic obstructive pulmonary disease. Am J Respir Crit Care Med. 2001;164(8 Pt 1):1414-1418.

30. Serres I, Gautier V, Varray A, Préfaut C. Impaired skeletal muscle endurance related to physical inactivity and altered lung function in COPD patients. Chest. 1998;113(4):900-905.

31. Gan WQ, Man SFP, Senthilselvan A, Sin DD. Association between chronic obstructive pulmonary disease and systemic inflammation: a systematic review and a meta-analysis. Thorax. 2004;59(7):574-580.

32. Wouters EF, Reynaert NL, Dentener MA, Vernooy HJ. Systemic and local inflammation in asthma and chronic obstructive pulmonary disease. Is there a connection? Proc Am Thorac Soc. 2009;6(8):638-647.
33. Després JP, Lemieux I. Abdominal obesity and metabolic syndrome. Nature. 2006;444(7121):881-887.

34. Hosogai N, Fukuhara A, Oshima K, et al. Adipose tissue hypoxia in obesity and its impact on adipocytokine dysregulation. Diabetes. 2007; 56(4):901-911.

35. Sauleda J, García-Palmer F, Wiesner RJ, et al. Cytochrome oxidase activity and mitochondrial gene expression in skeletal muscle of patients with chronic obstructive pulmonary disease. Am J Respir Crit Care Med. 1998;157(5 Pt 1):1413-1417.

36. Schols AM, Broekhuizen R, Weling-Scheepers CA, Wouters EF. Body composition and mortality in chronic obstructive pulmonary disease. Am J Clin Nutr. 2005;82(1):53-59.

37. Dallman MF, la Fleur SE, Pecoraro NC, Gomez F, Houshyar H, Akana SF. Minireview: glucocorticoids-food intake, abdominal obesity, and wealthy nations in 2004. Endocrinology. 2004;145(6):2633-2638.

38. O'Leary VB, Marchetti CM, Krishnan RK, Stetzer BP, Gonzalez F, Kirwan JP. Exercise-induced reversal of insulin resistance in obese elderly is associated with reduced visceral fat. J Appl Physiol. 2006; 100(5):1584-1589.

39. Burke GL, Bertoni AG, Shea S, et al. The impact of obesity on cardiovascular disease risk factors and subclinical vascular disease: the Multi-Ethnic Study of Atherosclerosis. Arch Intern Med. 2008;168(9): 928-935.
International Journal of COPD

\section{Publish your work in this journal}

The International Journal of COPD is an international, peer-reviewed journal of therapeutics and pharmacology focusing on concise rapid reporting of clinical studies and reviews in COPD. Special focus is given to the pathophysiological processes underlying the disease, intervention programs, patient focused education, and self management protocols.

\section{Dovepress}

This journal is indexed on PubMed Central, MedLine and CAS. The manuscript management system is completely online and includes a very quick and fair peer-review system, which is all easy to use. Visit http://www.dovepress.com/testimonials.php to read real quotes from published authors. 